\title{
PERCEPÇÃO DOS OFEITOS DO COOPERATIVISMO NO SUL DE MINAS GERAIS
}

\author{
Lidiany dos Santos SOARES ${ }^{1}$ \\ Roberta Bessa Veloso SILVA ${ }^{2}$ \\ Eric Batista FERREIRA ${ }^{3}$
}

\begin{abstract}
${ }^{1}$ Instituto Federal do Sul de Minas, campus Machado. E-mail: lidysts@msn.com.
${ }^{2}$ Universidade José do Rosário Vellano - UNIFENAS. E-mail: bessaveloso@yahoo.com.br

${ }^{3}$ Universidade Federal de Alfenas - UNIFAL. E-mail: Eric.ferreira@unifal-mg.edu.br
\end{abstract}

Recebido em: 27/03/2016 - Aprovado em: 25/05/2016 - Disponibilizado em: 30/07/2016

\begin{abstract}
Resumo: As cooperativas agropecuárias caracterizam-se pelos serviços prestados aos associados, com recebimento ou comercialização da produção conjunta, armazenamento e industrialização, além da assistência técnica, educacional e social. O estudo analisou a percepção dos cooperados em relação aos benefícios obtidos através das cooperativas e, ainda, a visão das cooperativas em relação à sua atuação junto aos seus cooperados, tendo como objetivo principal avaliar a importância das cooperativas no mercado agrícola para seus associados., através da promoção de benefícios que justifiquem sua existência. Verificou-se que a satisfação dos cooperados está fortemente relacionada com o atendimento das demandas financeiras e de assistência técnica, sendo considerados como vantagens significativas do vínculo cooperativista. Os resultados revelaram ainda que as cooperativas, embora manifestem facilidade de acesso, desconhecem a percepção de seus cooperados em relação aos benefícios oferecidos, pouco incentivam a $\mathrm{p}^{\cdots \cdots}$-ação através de cursos cooperativistas e ainda nas decisões tomadas em assembleias.
\end{abstract}

Palavras-chave: Cooperativismo; Benefícios; Cooperativas Agropecuárias.

Abstract: The agricultural cooperatives are characterized by services provided to members, with receipt or marketing of joint production, storage and industrialization, as well as technical assistance, educational and social. The study examined the perceptions of members in relation to the benefits obtained through cooperatives and the vision of cooperatives in relation to their performance along to its cooperative members, having as main objective to evaluate the importance of cooperatives in agricultural market to its members through promotion of benefits that justify its existence. The method of investigation used guided by qualitative approach to analysis and interpretation of data collected and as methodological procedure was employed multiple case studies - that allowed the survey data that contributed to the research problem raised elucidation. The data were collected through structured questionnaire with closed questions to cooperative members and interviews conducted by the three agricultural cooperatives of southern Minas Gerais. It was found that the satisfaction of cooperative members is strongly related to the fulfillment of demands financial and technical assistance, being considered as significant advantages of cooperative ties. Although cooperatives studied do not always offer the best prices, both in the sale of supplies as in the negotiations of the products deposited, there was the satisfaction of the majority of members, however, with little involvement or interest in decisions of cooperatives. The results revealed that although cooperatives are ease of access, unaware of the perception of their members in relation to the benefits and little participation are encouraged through cooperative courses and on the decisio in in meetings.

Keywords: Cooperatives. Benefits. Agricultural Cooperatives.

\section{Introdução}

Necessariamente, as cooperativas são associações de pessoas que se unem, através de princípios democráticos, com o objetivo de suprir necessidades econômicas, atuando como instituição política e, paralelamente, como um empreendimento econômico. Seu caráter específico resulta da forma de articular a organização e da promoção social de seus cooperados, e ainda de produzir algum bem ou serviço com relativa eficiência econômica. 
As

cooperativas

agropecuárias

cumprem importante função sob o aspecto econômico e social, especialmente pelo fato de se apresentarem, em muitas regiões, como uma das poucas possibilidades de valorização da produção rural, através da agregação de valor, bem como da inclusão de pequenos e médios produtores em mercados onde existem barreiras à entrada de novos concorrentes. Possuem estrutura que atende às necessidades de assistência técnica aos produtores, além de indiretamente oferecer muitos outros benefícios, garantindo melhor produção e possibilitando maior ganho pelo cooperado na venda de seus produtos.

O sistema cooperativista, além da importância econômica, representa importância social, especialmente em certos municípios e regiões, pois é o único meio que os agricultores possuem de organizar e comercializar sua produção.

Para que o cooperativismo seja efetivo e resulte no alcance dos objetivos de seus cooperados, surge a necessidade de conhecer a percepção destes e das cooperativas em relação aos benefícios proporcionados, a fim de subsidiar estas organizações, no planejamento de suas estratégias mercadológicas e de relacionamento com seus clientes. Este trabalho tem por objetivo contribuir para a reflexão sobre a importância das cooperativas, em especial as agropecuárias, para a obtenção de vantagens no mercado agrícola pelos seus cooperados.

\section{Fundamentação teórica}

\subsection{O cooperativismo agropecuário brasileiro}

Segundo Campos (2000), a partir de 1906, as cooperativas rurais começaram a surgir nos centros onde existia criação de gado, atuando no ramo de laticínios. No Brasil, ex-trabalhadores das fazendas de café iniciaram um tipo de produção mercantil, com um sistema de comercialização cujo objetivo era quebrar a superioridade dos intermediários que, na época, era significativa. Desta forma, ocorreu a mudança de uma produção camponesa de gêneros alimentícios para uma produção mercantil, o que culminou no surgimento do cooperativismo como solução momentânea para o enfraquecimento dos intermediários.

No setor agropecuário, o qual ganhou mais notoriedade em nosso país face às características da produção rural brasileira, o cooperativismo foi o elemento que unificou os esforços dos pequenos produtores familiares e foi também a fórmula encontrada para que se defendessem das pressões e interesses dos mais poderosos situados no comércio ou na indústria. Tem sido o principal responsável pela resistência dos pequenos produtores no enfrentamento de 
todos os percalços que a agricultura vem enfrentando nos últimos anos (SEBRAE, 2012).

As cooperativas, segundo Couvaneiro (2004), proporcionam condições de aprendizado, onde é possível encontrar novas formas para solucionar problemas comuns, atendendo às carências sentidas pela população rural, que acredita na possibilidade de trabalhar a terra em benefício próprio, através da criação de associações cooperativas.

O Serviço Nacional de Aprendizagem do Cooperativismo - SESCOOP - relacionou, em seu relatório de gestão 2012, a distribuição das cooperativas brasileiras de acordo com o ramo de atividade e região de atuação, no qual se verifica que as cooperativas do ramo agropecuário totalizam 1.528 empresas, representando $23,2 \%$ do total das cooperativas existentes no país. A maior concentração destas cooperativas encontra-se na Região Sudeste, com 410 cooperativas agropecuárias (SESCOOP, 2013).

Entre outros fatores, a profissionalização gerencial, a evolução da tecnologia, modernização de máquinas e equipamentos, o planejamento produtivo e, ainda, a redução de custos necessária para que as cooperativas enfrentem a competitividade da economia de mercado, compõem fortes razões para a adoção de estratégias de cooperação nestas empresas. Os cooperados necessitam e desejam que suas cooperativas agropecuárias tenham maior força e, ainda, que promovam a valorização de sua produção, proporcionando melhores condições econômico-sociais. Sendo assim, diante das situações impostas pela competitividade do mercado, e para atender às demandas de seus cooperados, as cooperativas necessitam atuar como organizações estruturadas de forma enxuta e com agregação de valor em suas atividades. Para que isto aconteça, faz-se necessário que os dirigentes definam estratégias que fortaleçam e tornem competitivas, as suas cooperativas (PINHO, 1977).

\subsection{Gestão da sociedade cooperativa}

A gestão das cooperativas deve se pautar nos seus valores e princípios, estabelecendo políticas de recursos humanos para o quadro de cooperados, conforme destaca Davis (2004). Estas organizações necessitam atuar de forma cooperativa em todos os níveis de gestão, sejam eles corporativos, de negócios, estratégicos, operacional ou institucional.

Sette (2010) argumenta que a competição tornou-se mais acirrada com o aumento da população, com a evolução tecnológica e do conhecimento, fazendo com que a utilização racional dos recursos seja fator determinante para o sucesso ou fracasso de uma organização. Sendo assim, a aplicação 
do processo administrativo nas áreas funcionais das organizações, através do planejamento, organização, direção e controle é o caminho para a promoção do uso racional dos recursos nas organizações.

Com relação às tendências da administração e do cooperativismo, Oliveira (2012, pp.5-15) observou que a evolução da administração está relacionada com a evolução das cooperativas, pois estas organizações são clientes e também fornecedoras das tendências da administração. Ao longo dos últimos anos, as cooperativas vêm apresentando melhorias que devem se fortalecer ainda mais no futuro.

\subsection{A participação dos cooperados nas cooperativas}

As cooperativas possuem características específicas que as diferenciam das outras organizações econômicas. São empresas de participação, ou seja, os cooperados participam tanto das operações, como nas decisões da cooperativa (FERREIRA, 1999).

Um fator importante a destacar é que as pessoas apenas participam daquilo que possuem interesse e que as motiva a participar. A interação entre cooperado e cooperativa promove maior confiança do associado e a crença de que os objetivos serão alcançados e de que haverá avanços, com a união e a participação de todos (RICCIARDI, 1996).
Embora a participação social dos cooperados seja importante, poucas ações são feitas para incentivá-la, ficando a mesma restrita ao campo econômico da cooperativa, através da entrega da produção pelos cooperados e da procura por vantagens obtidas através de serviços e menores preços para sua produtividade. Esta afirmativa, constatada por Stephanou e Villwock (2007), foi verificada em investigação feita sobre a percepção dos membros de uma cooperativa em relação à democracia existente. De acordo com os autores, a preocupação limita-se à questão financeira, com atenção dos cooperados voltada para os resultados, sem importarem-se com o modo com que estes possam ser alcançados.

No caso das cooperativas agropecuárias, existem dois pontos importantes, segundo Bialokorski (2012), que são os processos de educação e o número de associados da organização, sendo que este se apresenta como um fator importante, uma vez que o crescimento econômico da cooperativa está relacionado diretamente com o aumento no número de cooperados. Este aumento acaba sendo prejudicial para que os cooperados participem, resultando em custos. Há, ainda, a possibilidade de ocorrer menor acompanhamento junto aos membros e, sendo assim, a menor participação pode resultar em um menor compromisso na relação cooperado $\mathrm{x}$ cooperativa. 
Como exemplo, em uma cooperativa com 20 associados, o voto relativo de cada um deles apresenta 1/20 de poder de decisão, podendo haver maior expressão nas assembleias gerais, mas em uma cooperativa com 1.000 associados, cada voto apresenta 1/1.000 do poder de decisão e uma probabilidade de menor expressão em assembleia geral. Assim, conforme é maior o número de associados, há uma tendência de que os custos relativos de oportunidade de participação sejam maiores que os benefícios em decorrência de maior divisão relativa de direitos de decisão (BIALOKORSKI, 2012 p. 150).

Ao observar cooperativas agropecuárias, verificou-se a existência inversamente proporcional entre participação e número de associados, conforme demonstrado na Figura 1. Pode-se, também, associar a maior participação dos cooperados, em função da dispersão geográfica do quadro de associados, o que pode fazer com que o custo da participação seja mais dispendioso para o associado. Bialokorski (2012) afirma que cooperativas com grande número de cooperados podem promover assembleias prévias e reuniões preparatórias em núcleos de produtores, a fim de minimizar este problema.

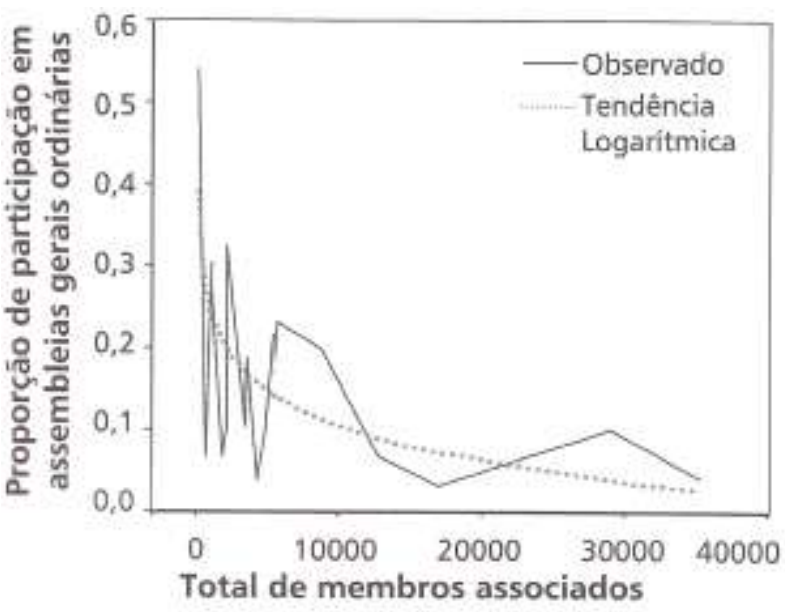

Figura 1. Relação entre a participação dos associados em Assembleias Gerais Ordinárias, em proporção ao número total de associados de uma Cooperativa. Fonte: Adaptado de Bialokorski (2012).

Com este entendimento, Zuurbier (1997) destaca que quanto maior o número de associados, maiores são os desafios para atender às necessidades de comunicação de visões de futuro, estratégia, planos de procedimentos, investimentos e novas ações nas cooperativas. A participação tem se destacado nos últimos anos, nas áreas de sociologia, economia, filosofia, ciências políticas e administração de empresas, caracterizando-se como um processo onde os seus integrantes são ativos na formação da estrutura e no planejamento dos objetivos. Este modelo de participação pode ser dividido nos níveis econômico - com o aporte de capital na cooperativa e nas operações comerciais existentes; administrativo através da atuação dos cooperados no planejamento, direção e controle da 
cooperativa, e social - com promoção de benefícios sociais aos cooperados.

\subsection{Vantagens do associativismo para o cooperado}

Os benefícios das sociedades cooperativas estão ligados à redução dos custos obtida com a integração vertical, promovendo melhores negociações para a compra de insumos e consequente economia de escala (SEXTON, 1986).

Para Bialoskorski (2001), as vantagens das empresas cooperativas estão relacionadas com a utilização correta de algumas particularidades, como por exemplo: a possibilidade de melhor coordenação da cadeia agroalimentar como um todo, pelo maior contato mantido com o produtor; o estabelecimento conjunto de estratégias corporativas através das assembléias gerais de associados; a maior clareza na transferência de preços, oportunidades e de informação.

Utilizando-se do modelo estruturaconduta-desempenho, Sexton demonstrou que as cooperativas podem minimizar os efeitos negativos de uma estrutura de mercado concentrada. Adotando como referencial a Teoria dos Mercados Contestáveis, demonstrou ainda que uma cooperativa é capaz de alterar o comportamento das empresas já existentes no mercado, promovendo condições perfeitas de competitividade.
Como cooperado, o produtor pode ainda obter garantia de mercado para sua produção, o que certamente não aconteceria, se tentasse negociar seu produto sozinho (com exceção dos contratos já negociados).

Outra vantagem reconhecidamente do cooperativismo está na prática direta da democracia através do direito de voto e, ainda, nas possibilidades de capacitação pessoal e profissional oferecidas aos cooperados. Através dos departamentos técnicos, as cooperativas atuam como multiplicadoras de conhecimentos, com a disseminação de informações fundamentais para o desempenho de suas atividades, em todos os ramos, e especialmente, no cooperativismo de produção (LIMBERGER, 1996).

\section{Procedimentos metodológicos}

Para o desenvolvimento, adotou-se o estudo de casos múltiplos, sendo empregado o método qualitativo. A pesquisa foi classificada como descritiva e exploratória, possibilitando conhecer aspectos particulares da relação cooperado/cooperativa.

A pesquisa foi realizada junto aos cooperados, produtores agrícolas das cooperativas selecionadas, não havendo a definição de um grupo específico de pessoas, com entrevistas feitas na sede das cooperativas, mediante o comparecimento dos cooperados para aquisição de insumos ou para 
a resolução de outros assuntos. Além dos cooperados, foram entrevistados os gestores das três cooperativas, denominadas neste estudo de Alfa, Beta e Gama, possibilitando ampliar as comparações sobre a percepção de ambos.

As cooperativas investigadas possuem atuação e cooperados em vários municípios da região Sul de Minas, com abrangência em: Cambuquira, Campanha, Carmo da Cachoeira, Cordislândia, Eloi Mendes, Heliodora, Jesuânia, Lambari, Machado, Monsenhor Paulo, Natércia, Poço Fundo, São Gonçalo do Sapucaí, Silvianópolis, Três Corações, Turvolândia e Varginha.

O levantamento dos dados primários foi feito através de aplicação de questionários de pesquisa composto de 29 questões, sendo quatro diretas, para a identificação do perfil dos cooperados, e 25 questões fechadas que atenderam ao propósito da pesquisa.

A coleta de dados foi realizada com aplicação direta do instrumento de pesquisa aos cooperados das cooperativas e, ainda, com entrevista realizada junto aos gestores das instituições, visando obter o maior número de informações possíveis para avaliar a visão dos cooperados e também das cooperativas em relação aos benefícios promovidos através do cooperativismo. Ao todo, foram entrevistados 136 cooperados, sendo 54 da cooperativa Alfa, 39 da cooperativa Beta e 43 da cooperativa Gama.
A cooperativa Alfa possui 1.400 cooperados ativos, enquanto a Beta possui 1.825 e a Gama conta com 4.585 associados.

Após a organização e apresentação dos dados através dos gráficos de colunas e setores, foi aplicado o teste qui-quadrado para relacionar as variáveis de interesse. Neste sentido, avaliou-se se o fator denominado satisfação dos cooperados não estava relacionado (independência) com as demais questões de interesse, sendo realizado um teste de independência (nível nominal de significância de 5\% e 1\%) com a seguinte estatística (BUSSAB; MORETTIN, 2003):

$$
Q^{2}=\sum_{i=1}^{r} \sum_{j=1}^{s} \frac{\left(o_{i, j}-e_{i, j}\right)^{2}}{e_{i, j}}
$$

em que $r$ e $s$ representam o número de linhas e colunas (tabela de dupla entrada), respectivamente, $o_{i, j}$ representam as frequências observadas e $e_{i, j}$ as frequências esperadas.

As hipóteses testadas foram: Hipótese nula $-\left(\mathrm{H}_{0}\right)$ : A satisfação dos cooperados independe da questão de número $x$, sendo $x$ a questão de interesse a ser comparada. Hipótese alternativa $\left(\mathrm{H}_{1}\right)$ : A satisfação dos cooperados depende da questão de número $x$.

Para todas as análises foi utilizado o software estatístico R, versão 3.2.3 (R CORE TEAM, 2015). 


\section{Resultados e Discussão}

Conforme relatado pelos gestores, as organizações cooperativas são oriundas de associações de produtores rurais, que identificaram no cooperativismo um caminho para atingir seus objetivos comuns.

Com mais de 50 anos de atuação no mercado, as cooperativas investigadas possuem um grupo diretor composto de $67 \%$ de cooperados com pós-graduação e os outros $33 \%$ graduados, confirmando um elevado nível de formação educacional. Além disto, todos os dirigentes já realizaram cursos de capacitação oferecidos pelo Serviço Nacional de Aprendizagem do Cooperativismo SESCOOP.

A orientação técnica de manejo no campo é um fator relevante na relação entre a cooperativa e seus cooperados. Conforme a Figura 2, verificou-se que este apoio é sempre prestado em $71 \%$ dos casos, o que demonstra a forte participação das cooperativas na assessoria aos cooperados em relação às suas demandas por conhecimentos técnicos.

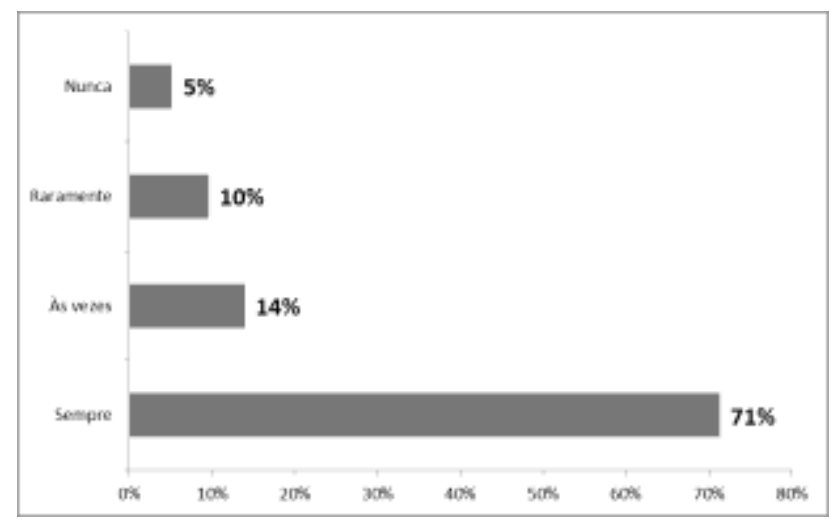

Figura 2. Serviços de orientação técnica. Fonte: Elaborada pelos autores.
Bialokorski (2001) afirma que, devido à escassez de capital, bastante comum na atividade agrícola, para manter um empreendimento, é necessário porte para possibilitar as compras em comum ou a armazenagem e o processamento da produção.

De acordo com a Figura 3, a estrutura para armazenamento da produção das cooperativas investigadas e, também, para atendimento aos cooperados, foi considerada adequada por mais de $80 \%$ do grupo pesquisado, revelando que os cooperados percebem os investimentos realizados para garantir o bom atendimento das suas necessidades.

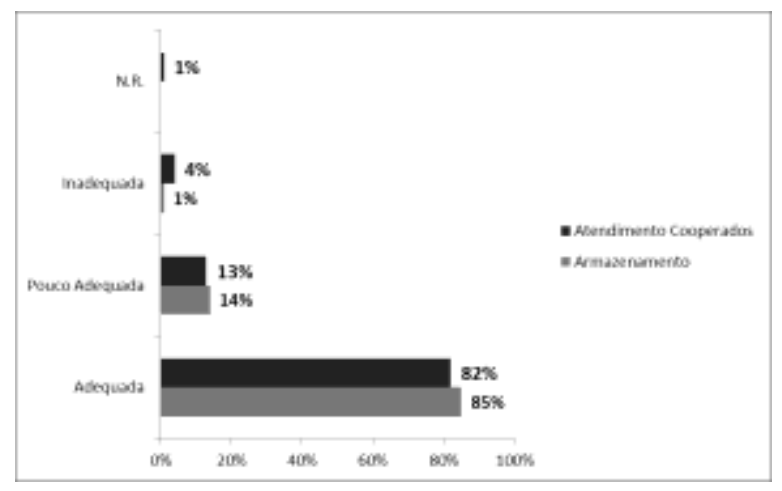

Figura 3. Estrutura física das cooperativas. Fonte: Elaborada pelos autores.

Dentre os benefícios promovidos pelo cooperativismo aos seus cooperados e à sociedade, a Organização das Cooperativas Brasileiras - OCB aponta o preço dos produtos e a coordenação de todo sistema agroindustrial de forma articulada, como forma de atendimento às necessidades de seus cooperados. 
Em relação à prática de preços realizada pelas cooperativas para a venda de insumos, observou-se que $51 \%$ dos cooperados afirmaram que, às vezes, os preços são menores que os de mercado e $10 \%$ alegaram que raramente os preços são menores.

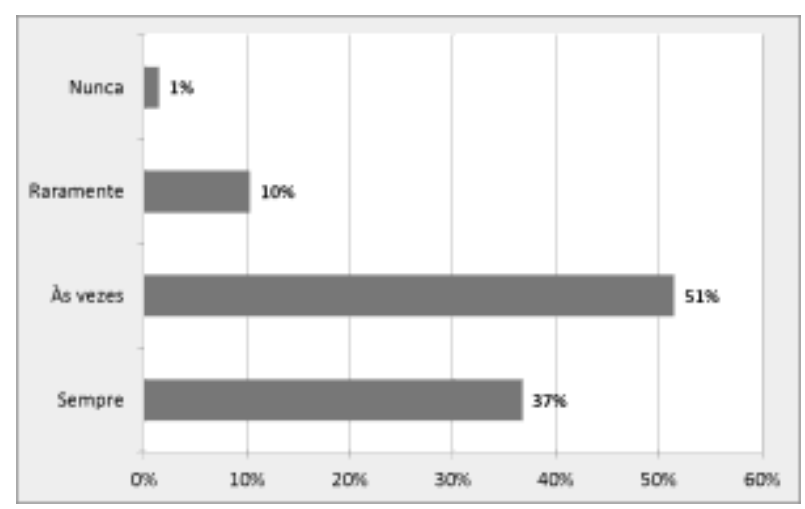

Figura 4. Prática de preços das cooperativas comparada aos preços de mercado.

Fonte: Elaborada pelos autores.

O teste de Qui-quadrado, ao nível de $5 \%$ de significância, confirmou uma associação estatisticamente significativa entre os preços praticados pelas cooperativas e a satisfação dos seus cooperados $(\mathrm{P}<0,05)$.

Analisando a percepção das cooperativas em relação ao seu próprio preço praticado, comparado com o mercado, verifica-se que $67 \%$ dos gestores das cooperativas relataram que os preços são sempre menores que o mercado, conflitando com a visão de seus cooperados.

Conforme Souza (2007), a fidelidade do cooperado pode ser promovida de várias formas. Uma delas é através da criação de ações que valorizem seu trabalho, como, por exemplo, com o fornecimento de insumos com menores custos e melhores condições.

Foi demonstrado que, apesar de $51 \%$ dos cooperados relatarem que, às vezes, os preços das cooperativas são menores que os praticados pelo mercado, $66 \%$ do total de cooperados entrevistados sempre compram na cooperativa, conforme pode ser observado na Figura 5, revelando que a maior parte prefere adquirir seus insumos na sua própria empresa.

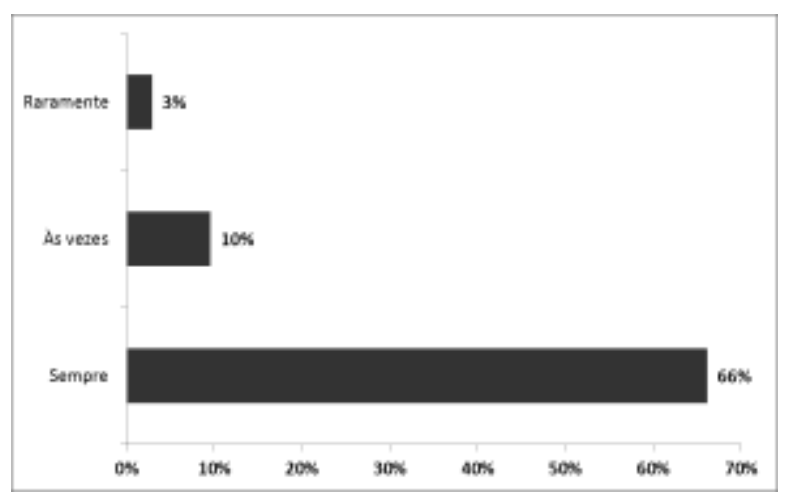

Figura 5. Aquisição de insumos na cooperativa pelos cooperados.

Fonte: Elaborada pelos autores.

Salienta-se que, do grupo que relatou que às vezes os preços das cooperativas são menores que os preços praticados pelo mercado, $35 \%$ sempre compram seus insumos na cooperativa, reforçando o entendimento da fidelização dos cooperados em suas relações comerciais com as cooperativas.

Além da maioria dos cooperados adquirirem os insumos necessários nas suas cooperativas, sua relação de fidelidade estende-se para a venda da produção agrícola, pois $60 \%$ dos associados sempre negociam 
seus produtos nas suas cooperativas. Neste quesito, vale considerar que $9 \%$ dos cooperados raramente vendem sua produção para as cooperativas e $4 \%$ nunca negociaram seus produtos com suas empresas.

Esta fidelidade é mais bem percebida, conforme pode ser visto na Figura 6, onde $54 \%$ dos cooperados afirmaram que as cooperativas, às vezes, negociam a venda da produção depositada com melhores preços que o do mercado. Nesta análise, verifica-se que ainda que as cooperativas, algumas vezes, não negociem os produtos dos seus cooperados com os melhores preços, estes continuam vendendo seus produtos através destas instituições.

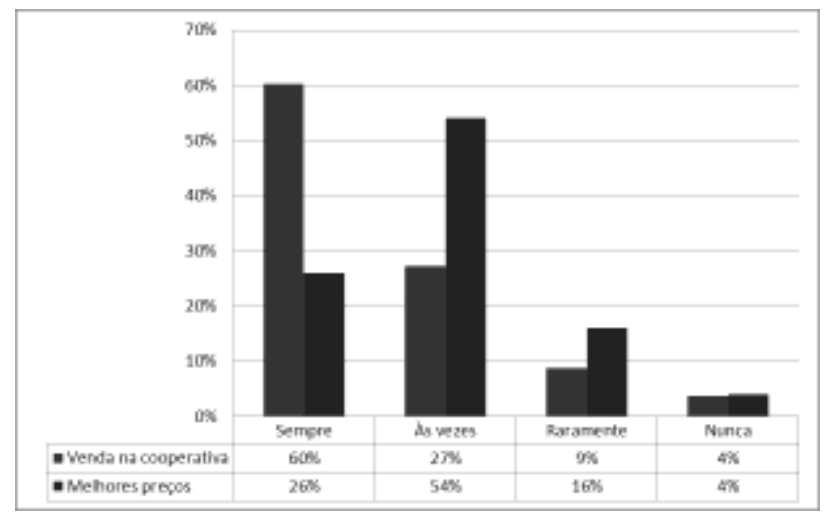

Figura 6. Venda da produção agrícola através das cooperativas e obtenção de melhores preços nas negociações pelos cooperados. Fonte: Elaborada pelos autores.

Em relação à promoção de eventos e cursos que abordem sobre cooperativismo, além de propiciar aproximação com o cooperado, ao conhecer melhor sua empresa, contribui para que se interesse por ela, apoiando-se na gestão e melhorando sua participação. Stephanou e Villwock (2007) afirmaram que poucas ações são feitas para incentivar a participação social dos cooperados, pois as cooperativas se restringem ao campo econômico em sua atuação. Esta afirmativa pode ser observada na Figura 7, uma vez que os $65 \%$ dos cooperados entrevistados nunca foram convidados a participar de algum curso sobre cooperativismo. Percebe-se que 39\% dos cooperados já foram convidados para cursos e que $35 \%$ já participaram destes eventos. Desta forma, a promoção de eventos direcionados teve a participação dos cooperados, na medida em que foram feitos convites para a participação.

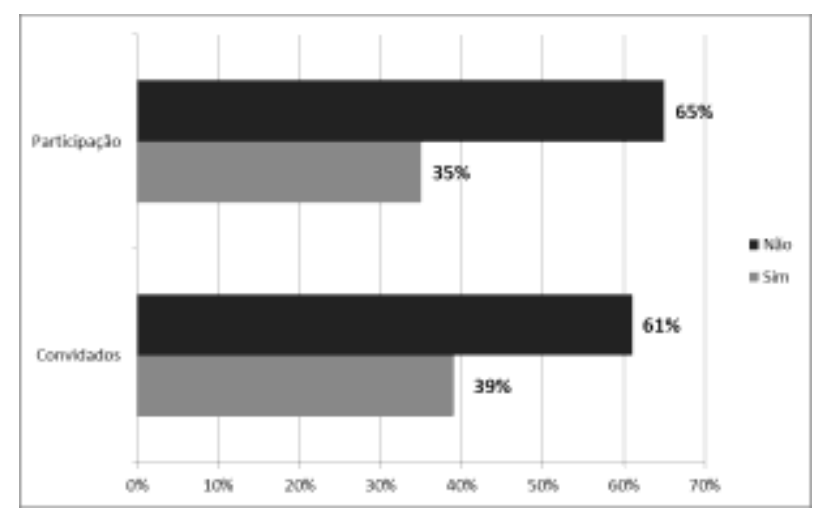

Figura 7 - Promoção de cursos sobre cooperativismo pelas cooperativas e participação dos cooperados. Fonte: Elaborada pelos autores.

Quando os gestores das cooperativas foram questionados sobre a qualidade em relação aos cadastros e a facilidade de acesso aos cooperados, $100 \%$ afirmaram a inexistência de qualquer dificuldade. A 
percepção de $66 \%$ dos cooperados revelou que a interação das cooperativas com seus cooperados ocorre através de dias de campo, workshops e assembleias. De acordo com Bialokorski (2012), quanto mais cooperados existentes em uma cooperativa, menor a sua participação, em função da dispersão geográfica e da maior divisão relativa dos direitos de decisão. Esta afirmativa se confirma neste trabalho, verificando-se, na Figura 8, que enquanto na cooperativa Alfa, com 1400 cooperados, $52 \%$ dos entrevistados relataram que raramente ou nunca participam das assembleias, na cooperativa Gama, com 4.585 cooperados, este percentual foi de $72 \%$.

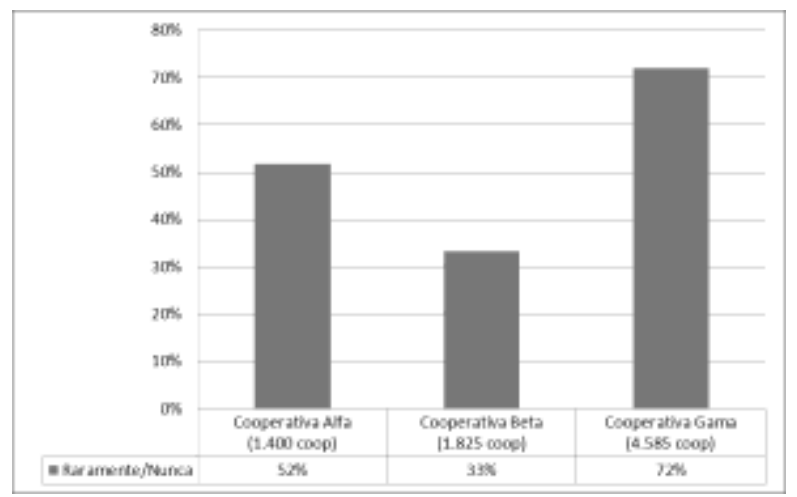

Figura 8. Participação dos cooperados nas Assembleias Gerais promovidas pelas cooperativas.

Fonte: Elaborada pelos autores.

De acordo com Maraschin (2004), os cooperados percebem a assistência técnica, além do acesso ao crédito e descontos obtidos, como vantagens do cooperativismo, sendo que a percepção destas vantagens está fortemente ligada à fidelização dos produtores.
Outra vantagem obtida pelo produtor, segundo Buainain e Souza Filho (2005) é a garantia de mercado para a sua produção e a possibilidade de garantir investimentos e planejar ações.

Dentre as várias vantagens apontadas pelos cooperados, a assistência técnica, a facilidade de pagamento das compras e do escoamento da produção mereceram destaque, por representarem 79\%, 66\% e 55\% respectivamente, conforme pode-se observar na figura 9. O atendimento preferencial é percebido em menor proporção pelos cooperados, como vantagem de se filiar a uma cooperativa, demonstrando que o atendimento dado aos demais clientes pode ser o mesmo fornecido aos cooperados, não existindo qualquer diferenciação.

O gestor da cooperativa Beta, em entrevista realizada, confirma esta informação, alegando falta de estrutura física e recursos humanos para atendimento diferenciado ou preferencial aos seus cooperados.

"O atendimento dos cooperados é igual ao dos demais clientes. Não temos um espaço diferenciado para atendê-los separadamente" (Relato do gestor da cooperativa Beta). 


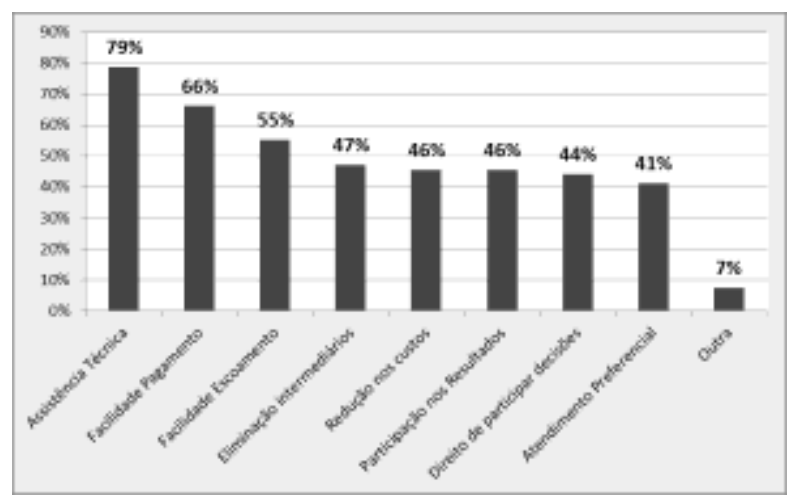

Figura 9 - Vantagens do vínculo cooperativista, segundo os cooperados.

Fonte: Elaborada pelos autores.

Em relação à percepção das cooperativas, $100 \%$ apontaram a assistência técnica, a facilidade de pagamento $\mathrm{e}$ escoamento dos produtos, a redução nos custos, participação nos resultados e o direito a participar de decisões como vantagens oferecidas aos seus cooperados. Em se tratando do atendimento preferencial aos cooperados e a eliminação de intermediários, estas questões foram consideradas como vantagens por $67 \%$ das cooperativas.

Ao analisar separadamente as cooperativas, constata-se que quanto maior o número de cooperados, tanto menor é a satisfação com a agilidade no atendimento, pois o nível de satisfação de $91 \%$ na menor cooperativa, decresce para $42 \%$ na maior.

Verifica-se, neste aspecto, que a satisfação dos cooperados em relação à agilidade sofreu uma redução de $54 \%$ entre a maior e a menor cooperativa, enquanto a satisfação com a qualidade sofreu redução de $9 \%$, conforme evidenciado na figura 10.

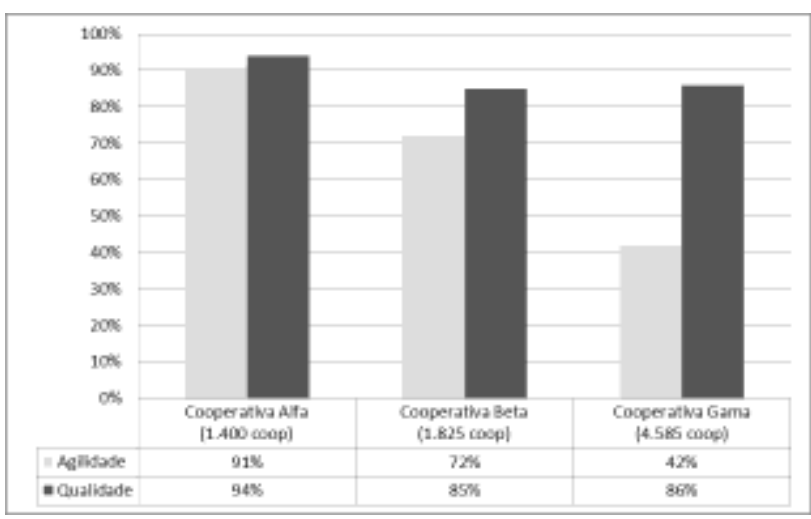

Figura 10. Satisfação dos cooperados com a qualidade e agilidade no atendimento de acordo com o número de associados das cooperativas.

Fonte: Elaborada pelos autores.

De modo geral, $65 \%$ dos cooperados estão totalmente satisfeitos com suas cooperativas e $28 \%$ pouco satisfeitos, demonstrando a importância deste segmento em suas atividades, conforme mostra a Figura 11.

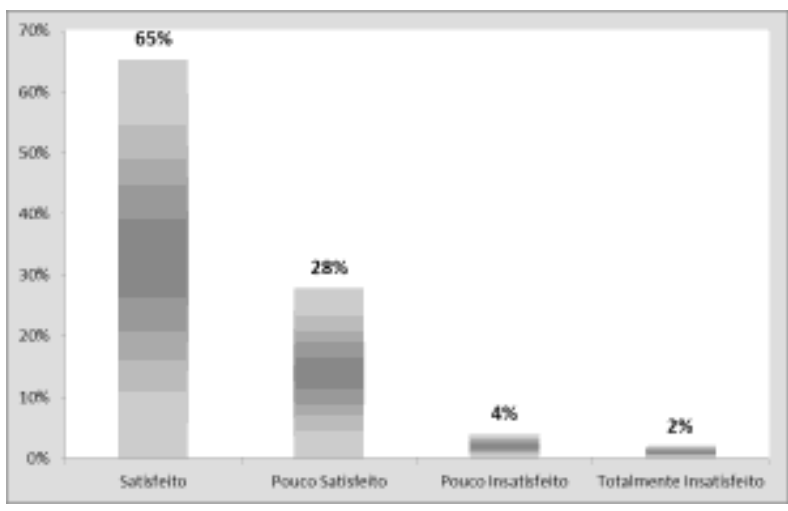

Figura 11. Satisfação geral dos cooperados. Fonte: Elaborada pelos autores.

\section{Conclusões}

Pode-se concluir que a maioria dos fatores considerados como importantes no relacionamento entre cooperativa e cooperado estão presentes nas atividades de apoio, 
alguns, porém abaixo dos níveis necessários para promover satisfação dos associados.

Os serviços de apoio técnico, que vão desde o processo correto de manejo no campo às assessorias que garantam a qualidade da produção, são oferecidos pelas cooperativas e responsáveis pela satisfação dos cooperados, sendo considerados por estes, como a maior vantagem do vínculo com as cooperativas.

A estrutura física disponibilizada pelas cooperativas, garantindo suporte para o armazenamento da colheita e também para atendimento aos cooperados, é considerada adequada pela maior parte dos seus associados.

Verificou-se divergência na percepção entre cooperativas e seus associados, em relação às questões financeiras e ao relacionamento existente. Enquanto os cooperados não se sentem totalmente amparados, alegando nem sempre obterem créditos para financiamento das safras, preços menores que o mercado, informações sobre o negócio e as mudanças nas legislações, as cooperativas, em sua totalidade, alegaram facilidade de acesso e comunicação com os cooperados e atendimento a todas as questões financeiras, na maioria das vezes. Percebe-se, com isso, a necessidade de que existam benefícios e serviços que sejam perceptíveis aos cooperados, incentivando-os cada vez mais a transacionar com as cooperativas e participar, evitando, assim, que as cooperativas sejam vistas como meras empresas comerciais do ramo agrícola.

Conscientes de que os preços praticados pelas cooperativas na venda de mercadorias e nas negociações de seus produtos algumas vezes não competem com o mercado, ainda assim, os cooperados mantêm uma relação de fidelidade, pois sempre adquirem insumos, vendem sua produção nas cooperativas e participam de cursos sobre cooperativismo, quando convidados.

Já em relação às Assembleias, a participação dos cooperados é, na maioria das vezes, relativamente baixa, especialmente nas cooperativas com maior número de associados.

A pesquisa demonstrou, ainda, que a satisfação dos cooperados está fortemente relacionada ao atendimento das necessidades financeiras e de assistência técnica, sendo apontados como um dos maiores benefícios do vínculo cooperativista.

Apesar de algumas divergências de opiniões entre cooperativas e cooperados, estes estão satisfeitos com suas cooperativas, especialmente quanto à qualidade dos serviços prestados, o que revelou o cumprimento do papel das cooperativas, com a promoção de vantagens e benefícios. Porém, apesar de satisfeitos, os cooperados não se sentem totalmente protegidos por elas, encarando-as como simples empresas do ramo agrícola, nas quais têm pequena participação 
nas decisões, ao contrário do que deveriam ter os donos de qualquer empreendimento.

\section{Referências Bibliográficas}

BIALOKORSKI N. S. Agronegócio cooperativo. In: BATALHA, M. (Org.). Gestão agroindustrial. São Paulo: Atlas. 2001.

BIALOKORSKI N. S. Economia e Gestão de organizações Cooperativas. 2. ed. São Paulo: Atlas. 2012.

BUAINAIN, A. M.; SOUZA, F. H. M. Hacia lá inclusión de los agricultores pobres em los mercados globalizados: relatório de pesquisa para IICA. Campinas. 2005.

BUSSAB, W.O.; MORETIN, P.A. Estatística Básica. 5. ed. $3^{\text {a }}$ tiragem. São Paulo: Editora Saraiva. 526 p. 2003.

CAMPOS JR. L.C. O Cooperativismo no Vale do Paranapanema: estudo das cooperativas Riograndenses, Agropecuária de Pedrinhas Paulista e Coopermota. Marilia: Unimar. 2000.

COUVANEIRO, C. S. Práticas Cooperativas Personalização e Socialização. Lisboa: Instituto Piaget. 2004.

DAVIS, P. Human resource management in cooperatives. Geneve: International Labour Office. 2004.

FERREIRA, R. N. Índices-padrão e situação econômica, financeira e político-social de cooperativas de leite e café da região sul do estado de Minas Gerais. (Dissertação de Mestrado). Universidade Federal de Lavras, Lavras, MG, Brasil. 1999.
LIMBERGER, E. Cooperativa empresa socializante. Porto Alegre: Imprensa Livre. 1996.

MARASCHIN, A.F. As relações entre produtores de leite e cooperativas: um estudo de caso na bacia leiteira de Santa Rosa - RS. (Dissertação de Mestrado) Universidade Federal do Rio Grande do Sul, Porto Alegre, RS, Brasil. 2004.

OCB - Organização das Cooperativas Brasileiras (n.d.). Princípios do cooperativismo. Disponível em: <http://www.brasilcooperativo.coop.br/site/ra mos/index.asp>. Acesso em: 20 Jun 2013.

OLIVEIRA, D. P. R. de. Manual de gestão das cooperativas: uma abordagem prática. 6. ed. São Paulo: Atlas. 2012.

PINHO, D. B. Economia e cooperativismo. São Paulo: Saraiva. 1977.

$\mathrm{R}$ CORE TEAM. $R: A$ language and environment for statistical computing. $\mathrm{R}$ Foundation for Statistical Computing, Vienna, Áustria. 2008.

RICCIARDI, L. Cooperativismo: uma solução para os problemas atuais. Vitória: Coopermídia. 96p. 1996.

SEBRAE - Serviço Brasileiro de Apoio às Micro e Pequenas Empresas. (n.d.). O Sistema Cooperativo e os ramos do Cooperativismo. Disponível em: <http://www.sebraemg.com.br/culturadacoop eracao/cooperativismo/o\%20sistema.htm>. Acesso em: 20 Jun 2013.

SETTE, R.S., ANDRADE, J.G.; TEIXEIRA, J.E.R.L. Planejamento e gestão $d a$ propriedade cafeeira. Lavras: UFLA. 2010.

SESCOOP - Serviço Nacional de Aprendizagem do Cooperativismo. (n.d.) Relatório de Gestão 2011. Disponível em: <http://www.ocb.org.br/Gerenciador/ba/arqui 
vos/Relatorio_de_Gestao_2011.pdf>. Acesso em: 20 Jun 2013.

SEXTON, R. J. Cooperatives and the forces shaping agricultural marketing. American Journal of Agricultural Economics, Menasha, v. 68, n. 2, p.1167-1172. 1986.

SEXTON, R. J. Imperfect competition in agricultural market and the role of cooperatives: a spatial analysis. American Journal of Agricultural Economics, Menasha, v. 72, n. 3, p. 709-720. 1990.

SOUZA, R.P. As transformações na cadeia produtiva do leite e a viabilidade da agricultura familiar: o caso do sistema COORLAC - SC. (Dissertação de mestrado) Universidade Federal do Rio Grande do Sul, Porto Alegre, RS, Brasil. 2007.

STEPHANOU, L.C.; VILLWOCK, L.H.M. $A$ percepção da democracia nas cooperativas médicas: o caso da Unimed Nordeste RS. Economia Solidária e Ação Cooperativa. ESAC, São Leopoldo, v. 1, n. 2, p. 143-150, jun. 2007.

ZUURBIER, P.J.P. União europeia e reorganização do cooperativismo europeu. Anais do Congresso Brasileiro de Cooperativismo, Brasília, DF, Brasil, 153171. 1997. 